\title{
A percepção sociolinguística e a indicialidade (indireta) de gênero
}

\author{
Marcus Garcia de SENE (1) \\ Universidade Estadual Paulista (UNESP)
}

\section{RESUMO}

Nesta conferência, o professor Ronald Beline Mendes discute os resultados de um estudo de percepção sociolinguística que examinou os significados sociais para os quais um determinado elemento linguístico pode apontar. No experimento reportado pelo conferencista, a variável em estudo foi a concordância nominal de número e o experimento foi realizado com base na técnica de matched-guise. Os resultados gerais sinalizam que a variável concordância nominal tem um efeito na percepção de como um determinado homem soa e, portanto, a concordância não padrão, além de

OPEN ACCESS

EDITADO POR

Raquel Freitag

AVALIADO POR Dany Thomaz Gonçalves

DATAS

Recebido: 01/07/2020

Aceito: 05/07/2020 Publicado: 23/07/2020

COMO CITAR

Sene, M. G. (2020),

A percepção sociolinguística e a indicialidade (indireta) de gênero. Revista da Abralin, v. 19, n. 2, p. 1-6, 2020. indiciar baixa escolaridade e classe socioeconômica (SCHERRE, 1988; 1994), também indicia (indiretamente) masculinidade.

\section{ABSTRACT}

In this conference, professor Ronald Beline Mendes discusses the results of a study on sociolinguistic perception which examined the social meanings to which a given linguistic element may point. In the experiment reported by the lecturer, the variable studied was agreement of nouns, and the experiment was carried out based on the matched-guise technique. The general results of the study reported by Mendes indicate that the variable nominal agreement has an effect on the perception of how a certain man sounds and, therefore, non-standard agreement, in addition to index low education and socioeconomic class (SCHERRE, 1988; 1994), it also index (indirectly) masculinity. 


\section{REVISTA DA ABRALIN}

PALAVRAS-CHAVE

Percepção sociolinguística. Gênero. Indexicalidade

\section{KEYWORDS}

Sociolinguistic perception. Gender. Indexicality.

Esta resenha tem como objeto a videoconferência do Prof. Dr. Ronald Beline Mendes, promovida pela Associação Brasileira de Linguística (ABRALIN) e intitulada de A percepção sociolinguística do 'soar gay'. A videoconferência foi transmitida pela internet, na Plataforma do Youtube, no dia 23 de junho de 2020, às 19 horas, e integra o conjunto de atividades do evento Abralin ao vivo. A conferência teve a duração de $2 \mathrm{~h}$ e contou com a mediação do doutorando Dany Thomaz Gonçalves, da Universidade Federal do Rio de Janeiro.

O professor Ronald é livre-docente docente pela Faculdade de Filosofia e Ciências Humanas da Universidade Estadual de São Paulo (2018) e professor associado da mesma universidade. Suas pesquisas concentram-se nos seguintes temas: variação, mudança, percepção sociolinguística e correlações entre categorias sociais e usos linguísticos.

A videoconferência está dividida em três partes, que são: (i) alguns pressupostos teóricos sobre a relação entre os elementos linguísticos e os significados sociais potenciais (relação indicial), (ii) informações metadiscursivas de uma pesquisa realizada pelo conferencista em 2007 sobre o que é "soar gay", e (iii) resultados de um experimento de percepção sociolinguística, em que as associações entre formas linguísticas e significados sociais são feitas implicitamente - a maioria dos resultados dessa pesquisa está disponível em sua tese de livre docência (2018).

Existem duas principais direções para os experimentos de percepção em sociolinguística, a primeira, grosso modo, examina como a variação linguística influencia nas informações sociais atribuídas ao falante, enquanto a segunda se dedica a avaliar como as informações sociais sobre um falante podem influenciar a percepção de uma determinada variável linguística (DRAGER, 2014). Na presente conferência, Mendes reporta, como resultado principal, o experimento do primeiro tipo, haja vista que o interesse dele é investigar os significados sociais para os quais um determinado elemento linguístico pode apontar.

A investigação dos elos, através dos quais as formas linguísticas invocam vários aspectos da estrutura social, tem permitido desvendar avaliações subjetivas das mais variadas. Um exemplo disso é o que apresenta Mendes, produtivamente, quando expõe, na terceira parte da conferência, o experimento de avaliações implícitas que tem como objetivo avaliar o efeito da variável concordância nominal padrão (CNp) na percepção de masculinidade. Não é novo o desejo em cotejar elementos linguísticos e a percepção de gênero e sexualidade, por exemplo. Pesquisas em língua inglesa já apresentam uma certa tradição com as pesquisas de Gaudio (1994), Smyth e Rogers (2001), Smyth et al. (2003) entre outras. Enquanto no Brasil, pesquisas de percepção sociolinguística de gênero e 


\section{REVISTA DA ABRALIN}

sexualidade começaram a ganhar força com a extensa produção do conferencista (MENDES, 2007; 2011; 2015; 2018) e motivou outras como as de Sene (2018; 2019) e Gonçalves (2019).

Em 2006, Labov menciona na segunda edição de seu livro sobre o Inglês de Nova York, que as abordagens experimentais, comparativamente aos estudos de produção, não haviam vingado na sociolinguística (LABOV, 2006 [1966]). Quase quinze anos após essa publicação, tem-se um cenário bem diferente, um exemplo a se destacar, pelo menos no Brasil, é o experimento de percepção sociolinguística apresentado por Mendes. A partir de construções estereotipadas apresentadas na segunda parte da conferência, em especial aquela sobre o fato de que "gays falam certinho", o conferencista, de forma pontual, propõe-se a investigar a seguinte hipótese: seria um homem percebido como alguém que soa menos masculino diante de concordância nominal padrão (CNp)?

Mesmo que essas construções estereotipadas sejam reações gerais apresentadas de forma espontânea e, aparentemente, sem qualquer correlação com os dados linguísticos objetivos, o que a população em geral acredita sobre a língua e a linguagem tem sido cada vez mais reconhecido como um objeto legítimo e importante de estudos empíricos. Nessa direção, Labov (2006 [1966]) salienta que:

“[...] nossos informantes não dispõem de um vocabulário com o qual possam avaliar a fala para nós. Dessa forma, nós precisamos não fazer perguntas diretas a eles, mas eliciar algum tipo de comportamento avaliativo que seja suficientemente sensível para refletir a influência de variáveis específicas e que possa ser analisado quantitativamente". (LABOV, 2006 [1966], p. 266)

Sobre eliciar um comportamento avaliativo e de forma implícita, sem que os participantes soubessem o que estavam avaliando, Mendes nos brinda com seu experimento que traduz, pelo menos por ora, o que há de mais moderno nos estudos de percepção, já que trabalha com gravações naturais, plataforma de questionário sofisticada e uma refinada ferramenta estatística. Com dois trechos de 4 falantes, retirados da amostra do SP2010 ${ }^{1}$, o professor, com auxílio do software PRAAT, cria estímulos pareados que contêm, por exemplo, um disfarce na versão padrão da $\mathrm{CN}$ e outro na versão não padrão da $\mathrm{CN}$ - conforme quadro abaixo.

1 O Projeto SP2010 reúne amostras da fala paulistana coletadas pelo Grupo de Estudos e Pesquisa em Sociolinguística da USP, na forma de gravações e transcrições, com o intuito de contribuir para a disseminação de trabalhos sociolinguísticos sobre essa variedade de fala. 


\section{REVISTA DA ABRALIN}

\begin{tabular}{c|c|c|c}
\hline A & B & C & D \\
\hline Jaime-s & Jaime- $\varnothing$ & Jaime-s & Jaime- $\emptyset$ \\
Lucas- $\varnothing$ & Lucas-s & Lucas- $\varnothing$ & Lucas-s \\
Carlos-s & Carlos- $\varnothing$ & Carlos-s & Carlos- $\varnothing$ \\
Robson- $\varnothing$ & Robson-s & Robson- $\varnothing$ & Robson-s \\
\hline
\end{tabular}

FIGURA 1 - Conjunto de estímulos elaborados para o experimento da CN² Fonte: Mendes (2020)

Apesar de os estímulos desenvolvidos não tenham sido apresentados para os participantes, Mendes detalha que os resultados de Carlos e Robson, por exemplo, soaram como homens menos efeminados, enquanto Jaime e Lucas foram percebidos como mais efeminados. Quando o professor analisa as respostas a partir dos estímulos que os participantes da pesquisa ouviram (se CN padrão ou CN não padrão), é possível verificar que todos os 4 informantes da pesquisa, quando ouvidos no disfarce de $\mathrm{CN}$ padrão, foram percebidos como mais efeminados do que quando ouvidos no disfarce não padrão da CN. Dito de outro modo, o que Mendes sumariza com os resultados é o fato de que a variável $\mathrm{CN}$ tem um efeito na percepção de como um determinado homem soaria e, portanto, a CN não padrão, além de indiciar baixa escolaridade e classe socioeconômica (como mostram outros estudos sociolinguísticos SCHERRE (1988; 1994), ela também indicia (indiretamente) masculinidade.

Isso ilustra que, no campo indicial da concordância nominal, para além de escolaridade e classe social, a masculinidade é um significado social potencial. Esse resultado pode não ser de fácil entendimento para todos que estavam online, uma vez que analises que enfatizam a relação entre elementos linguísticos e seus significados sociais, tal como realiza Mendes, é, de certa forma, nova no Brasil. No entanto, o conferencista, de forma didática, esclarece que indiciar masculinidade, por exemplo, não implica dizer que se você quer soar mais masculino, você deve usar CN não padrão, o fato é que a relação indicial não é nem essencial e nem necessária.

O professor exemplifica essa discussão quando traz o exemplo da pronúncia da palavra "gosta" realizada por alguns cariocas como "góixta", em que se pronúncia o "óix", como vogal média-baixa posterior ditongada [j] seguida da consoante fricativa palato-alveolar surda [ [] . A forma linguística [ojj] pode apontar para o significado social de "ser carioca", mas não por que existe algo essencialmente carioca na forma linguística em questão; pelo contrário, isso só é possível, já que "de tão frequente que se tornou a coocorrência da forma linguística e da identidade regional, uma se tornou "especialidade" da outra" (MENDES, 2018, p. 6).

Com essa discussão, o conferencista traz importantes contribuições para um questionamento maior, sobre o qual outros pesquisadores também estão interessados, que é: "quais elementos linguísticos levam um ouvinte a achar que um certo falante soa gay?". Vale destacar que essa pergunta se distancia de uma abordagem essencialista, visto que não é pertinente perguntar ou buscar

$2 \mathrm{O}$-s na frente dos nome dos falantes significa que é o estímulo criado com a variante padrão da CN, enquanto o zero fonético é o estímulo não padrão. 


\section{REVISTA DA ABRALIN}

identificar explicitamente se "ser gay significa falar de um certo modo" - não há um único "modo gay" de falar - e, ainda, um determinado homem pode "soar gay", mas não ser de orientação sexual gay e vice-versa. É nesse sentido que Mendes, de forma bastante sagaz, opta por "soar gay" no título de sua conferência.

Em resumo, a conferência é produtiva e sistemática, pois convida a todos a refletir sobre o avanço da pesquisa sociolinguística, em particular dos trabalhos de percepção de gênero e sexualidade. Além disso, Mendes mostra que, do ponto de vista linguístico, percepções relacionadas a intuições estereotipadas devem ser testadas por meio de metodologias adequadas, uma vez que já é de conhecimento de todos que a língua não só transmite conteúdo puramente informacional, como também reflete informações sociais.

\section{REFERÊNCIAS}

A percepção sociolinguística do 'soar gay'. Conferência apresentada por Ronald Beline Mendes [s.l., s.n], 2020. 1 vídeo (2h 4min 00s). Publicado pelo canal da Associação Brasileira de Linguística. Disponível em: https://www.youtube.com/watch?v=WIX8I1OY5Z8. Acesso em: 23 jun 2020.

DRAGER, K. Experimental Methods in Sociolinguistics. In: HOLMES, J.; HAZEN, K. (orgs.). Research Methods in Sociolinguistics: a pratical guide. A pratical guide. London: Willey Blackwell, 2014. p. 58-73.

GAUDIO, R. P. Sounding Gay: Pitch Properties in the Speech of Gay and Straight Men. American Speech, 69: 30-57, 1994.

GONÇALVES, D. T. Indexação Social da Sexualidade: Percepção da fala de Homens Gays Cariocas. Trabalho apresentado na ABRALIN50, 2019.

LABOV, W. The social stratification of English in New York City. 2nd edition. Cambridge: Cambridge University Press, 2006 [1966].

MENDES, R. B. What is 'gay speech' in São Paulo, Brazil. In: SANTAEMILIA, J. et al. (ed.) International Perspectives on Gender and Language. València: Universitat de València, 2007.

MENDES, R. B. Diminutivos como marcadores de sexo/gênero. Linguística, 8(1): 173-190, 2011.

MENDES, R. B. Diminutives and masculinity in Brazilian Portuguese. In: MILANI, T. (org.). Language and masculinities: Performances, intersections, dislocations. New York: Routledge, 2015.

MENDES, R. B. Percepção e performance de masculinidades: efeitos da concordância nominal de número e da pronúncia de /e/ nasal. Tese de Livre Docência. 225f. Universidade de São Paulo. 2018.

SENE, M. G. Vozes masculinas e orientação sexual: produção, variação e percepção sociofonética. In: X Seminário de Linguística da UNESP: História(s) e desafios da Linguística, 2018, Araraquara. Anais do X Seminário de Estudos Linguísticos da UNESP: História(s) e desafios da Linguística. Araraquara: Araraquara : FCL-UNESP, 2018. v. 1. p. 405-409.

SENE, M. G. Vozes masculinas: percepção, gênero e sexualidade. In: Pesquisas em Linguagem: diálogos com a contemporaneidade. São José do Rio Preto: UNESP, 2019. v. 1. p. 75-75.

SCHERRE, M. M. P. A Reanálise da concordância nominal em português. 1988. 555 f. Tese (Doutorado em Linguística) - Universidade Federal do Rio de Janeiro, Rio de Janeiro, 1988. 


\section{REVISTA DA ABRALIN}

SCHERRE, M. M. P. Aspectos da concordância de número no português do Brasil. Revista Internacional de Língua Portuguesa (RILP) - Norma e variação do Português. Associação das Universidades de Língua Portuguesa. n.12, p 37-49, dez. 1994. Disponível em: <http://www.ai.mit.edu/projects/dm/bp/scherre94-number.pdf>. Acesso em: 12 abr. 2013.

SMYTH, R; ROGERS, H. Searching for phonetic correlates of gay and straight- sounding voices. Toronto Working Papers in Linguistics, v. 8, p. 44-64, 2001.

SMYTH, R. et al. Male Voices and Perceived Sexual Orientation: Na experimental and Theoretical Approach. Language in Society, 32: 329-50. 2003 